\title{
Konsep Dakwah Islam Rahmatan Lil'alamin Dalam Majalah Bangkit
}

\author{
Arina Rahmatika, \\ STAI Sunan Pandanaran \\ Arina.eljawie@gmail.com \\ Ninda Khoirullina \\ STAI Sunan Pandanaran \\ nindakhoirullina90@gmail.com
}

\begin{abstract}
The purpose of this research is to discuss how the discourse of the concept of Islamic da'wah by Rahmatan Lil'alamin according to Bangkit Magazine is seen from its main ideas to the characteristics of its preaching. Islam is a religion that was revealed by Allah SWT to the Prophet Mubammad SAW which regulates the relationship between bumans and God and also regulates the relationship between humans and humans and the universe which benefits each other, therefore Islam has the principle of Rahmatan lil 'Alamin, which is a blessing for the universe. This research in extracting data using direct interviews to magazine administrators, literature study and documentation. From the research results, it can be found that Islam Rabmatan lil 'Alamin according to Bangkit Magazine is an Islam that is peaceful, just, tolerant and in accordance with the values of aswaja. The definition of Rahmatan lil 'Alamin is also not much different from the big concept of Islam which is in accordance with the teachings of NU (Nabdlatul Ulama). Islamic Perspective Rahmatan lil 'Alamin Bangkit Magainine is also sustainable with the characteristics of Islam Rahmatan lil' Alamin including non-violence, prioritizing peace, brotherhood, mutual respect and good things. As for the solution to restore the current image of Islam, namely by making Islam Rahmatan lil 'Alamin as a protector in preaching, with that Islam will also gradually create a vision full of tenderness and peace.
\end{abstract}

Keywords: Da'wa Islam, Rahmatan lil 'Alamin, Majalah Bangkit

\begin{abstract}
Abstrak
Tujuan penelitian ini membahas bagaimana bagaimana wacana konsep dakwah Islam Rahmatan Lil'alamin menurut Majalah Bangkit dilihat dari gagasan utamanya hingga karakteristik dakwahnya. Islam adalah agama yang diturunkan Allah SWT kepada Nabi Muhammad SAW yang mengatur hubungan manusia dengan Tuhan dan juga mengatur hubungan manusia dengan manusia serta alam jagat raya yang saling memberi manfaat, maka dari itu Islam memiliki prinsip Rahmatan lil 'Alamin yaitu rahmat bagi alam semesta. Penelitian ini dalam penggalian data menggunakan wawancara langsung kepada pengurus Majalah, studi pustaka dan dokumentasi. Dari hasil penelitian bisa ditemukan bahwa Islam Rahmatan lil 'Alamin menurut Majalah Bangkit adalah Islam yang damai, adil, toleran dan sesuai dengan nilai-nilai aswaja. Pengertian Rabmatan lil 'Alamin tersebut juga tidak jauh
\end{abstract}

Jurnal Dakwah dan Komunikasi

IAIN Curup-Bengkulu |E-ISSN: 2548-3366; P-ISSN: 2548-3293 
beda dengan konsep besar Islam yang sesuai dengan ajaran NU (Nahdlatul Ulama). Perspektif Islam Rahmatan lil 'Alamin Majalah Bangkit juga berkesinambungan dengan karakteristik Islam Rabmatan lil 'Alamin diantaranya yaitu tidak ada kekerasan, mengutamakan perdamaian, persaudaraan, saling menghargai dan hal-hal yang sifatnya baik. Adapun solusi untuk mengembalikan citra Islam sekarang yaitu dengan menjadikan Islam Rahmatan lil 'Alamin sebagai pelindung dalam berdakwah, dengan itu Islam juga akan menciptakan visi dengan penuh kelembutan dan kedamaian secara bertahap.

Kata Kunci: Dakwah Islam, Rahmatan lil 'Alamin, Majalah Bangkit

\section{Pendahuluan}

Islam adalah agama terakhir yang diturunkan oleh Allah dan hadir ditengah kehidupan massyarakat yang mampu mewujudkan kedamaian dan kasih sayang bagi manusia ataupun alam semesta. ${ }^{1}$ Islam hadir sebagai agama yang Rabmatan lil 'Alamin yang secara normatif dapat dipahami dari ajaran Islam berdasarkan akidah, ibadah dan akhlak yang dimiliki manusia. waktu 10 tahun dan pertama kali diterbitkan pada bulan Oktober 1979. Majalah Bangkit merupakan salah satu Majalah Islam yang berkantor di Kota Yogyakarta, salah satu media cetak Islam yang memiliki slogan "Santun dan Mencerdaskan" dengan semboyan diniyah-ilmiyah-ijtima'iyah. ${ }^{2}$ Dengan mengangkat tema ajarah Ahlussunnah Wal Jama'ah. Maksud dari semboyan tersebut adalah diniyah yang berasal dari bahasa arab dinun yang artinya agama. Sedangkan ilmiyah artinya ilmu dan ijtima'iyah artinya perkumpulan.

Bedasarkan pemaparan semboyan tersebut bisa disimpulkan bahwa Majalah Bangkit adalah majalah organisasi keagamaan yang memuat berita Islam sekitar NU (Nahdlatul Ulama). Sedangkan maksud dari slogan "Santun dan Mencerdaskan" adalah santun yang tidak provokatif dan mencerdaskan untuk masyarakat khusunya warga NU (Nahdlatul Ulama). Majalah Bangkit memang majalah Islam yang dikhususkan untuk warga NU (Nahdlatul Ulama). Dalam kontennya Majalah Bangkit hanya mempublikasikan informasi yang bersangkutan dengan NU dan harus berbasis Islam.

Penyajian konten Majalah Bangkit mencari informasi yang aktual di NU, jadi Majalah Bangkit tidak mengutamakan insiden yang sedang terjadi diluar tetapi Majalah Bangkit harus tetap berada pada pempublikasian yang bersifat Islami dan tentunya ke-NU-an dalam menebar Rahmat Ablussunnah Wal Jama'ah. Majalah Bangkit dalam memperkenalkan Rahmatan lil 'Alamin dengan dunia saat ini yaitu dengan cara menyebarkan konten Islam Rabmatan lil 'Alamin di semua jaringan media sehingga masyarakat itu lebih kenal kedamaian daripada kerusakan dan permusuhan.

${ }^{1}$ Asep Maulana Rahimat, Metodologi Studi Islam: Memabami Islam Rabmatan Lil'alamin (Yogyakarta: Gerbang Media, 2018), 3-4.

${ }^{2}$ Ahmad Zuhdi Muhdlor, "Majalah Bangkit" dalam https://www.nu.or.id/post/read/40223/majalah-bangkit. Diakses pada 14 Oktober 2020. 
Hal tersebut merupakan tantangan bagi Majalah Bangkit untuk menyebarkan Islam yang Rahmatan lil 'Alamin. Sebenarnya sejak dulu Islam sudah mempunyai tantangan daripada zaman sekarang. Tantangannya jelas orang-orang yang dalam dirinya tertanam api permusuhan, perusak orang lain, itu merupakan tantangan paling serius konsep Islam Rabmatan lil 'Alamin, karena konsep ini memberi kasih sayang dan kedamaian kepada orang lain. Pada kenyataannya tantangan untuk mengenalkan Islam Rabmatan lil 'Alamin dari dulu sampai sekarang tidak berubah. Justru semakin modern zaman, semakin sulit pula untuk meraih kejayaan Islam. Jadi, cara yang sesuai untuk mengenalkan Islam Rabmatan lil 'Alamin saat ini dengan mengusung keselarasan antara syari'at Islam dan tuntutan dunia modern.

Perbedaan penelitian ini dengan penelitian sebelumnya terletak pada pemaknaan Islam Rahmatan Lil'alamin yang dikembangkan oleh media massa. Jika penelitian sebelumnya masih terbatas penafsiran secara tematik hingga metode mengkampanyekan dan mentransformasikan konsep dakwah Islam Rahmatan Lil'alamin, maka penelitian ini lebih focus pada kajian bagaimana wacana konsep dakwah Islam Rahmatan Lil'alamin menurut Majalah Bangkit dilihat dari gagasan utamanya hingga karakteristik dakwahnya.

Adapun metode analisis data yang digunakan dalam penelitian ini adalah metode deskriptif-analisis, yang disusun kedalam 3 kategori yaitu reduksi data, penyajian data dan kesimpulan. Sedangkan untuk teknik pengumpulan data melalui wawancara langsung dengan redaktur Majalah Bangkit, dokumentasi dengan melihat berbagai wacana atau isu yang dikembangkan Majalah Bangkit mengenai Islam Rahmatan Lil'alamin dan studi pustaka melalui berbagai artikel dan buku untuk menunjang analisis kajian dakwah Islam Rahmatan Lil'alamin. Sumber data penelitian yang diperoleh secara langsung dengan wawancara Bapak Muhammadun sebagai ketua direktur, Bapak Ahmad Syaefudin, Ahmad Lailatu Sibyan, Ahmad Kholid Anwar dan Amrullah. Sumber data sekunder penelitian juga diperoleh melalui media perantara atau secara tidak langsung yang berupa Majalah Bangkit, Website Majalah Bangkit, buku dan jurnal yang berkaitan dengan Islam Rahmatan Lil'alamin.

\section{Hasil dan Pebahasan}

\section{a. Dakwah Islam Rahmatan lil 'Alamin}

Konsep Islam Rahmatan lil 'Alamin yang dilakukan oleh tim redaksi Majalah Bangkit harus sesuai dengan prinsip NU (Nahdlatul Ulama), karena Majalah Bangkit itu hanya sarana untuk menyebarluaskan ajaran-ajaran yang dianut oleh NU (Nahdlatul Ulama). Diantara prinsipnya yaitu dalam akidah ikut Imam Asy'ari dan Imam Maturidi, dalalm syari'ah ikut 4 mazhab, dalam tasawuf atau akhlaq ikut Imam Junaidi dan Imam Ghazali. ${ }^{3}$ Prinsip aqidah adalah dikelompokkan menjadi 6 pembahasan, yaitu : tentang Ke-Tuhanan, Malaikat,

\footnotetext{
${ }^{3}$ Ahmad Zuhdi Muhdlor, "Majalah Bangkit" dalam https://www.nu.or.id/oost/read/40223/majalah-bangkit. Diakses Pada 14 Oktober 2012.
} 
Kitab Suci, Rasul, Hari Akhir dan Qada Qadar. ${ }^{4}$ Jadi aqidah ini membahas mengenai Ke-Tuhanan dan sifat-sifat-Nya, Malaikat beserta tugasnya, dan Kitab Suci beserta kewahyuan-Nya, dan Qada' qadar hari akhir dan takdir Allah, yang baik maupun yang buruk. ${ }^{5}$

Prinsip Asy'ariah menerapkan sikap tawasuth (moderat) dalam beraqidah, sikap ini sangat diperlukan untuk merealisasikan kebijaksanaan dalam Islam. Empat Imam Mazhab tersebut yaitu Imam Hanafi, Imam Maliki, Imam Syafi'i dan Imam Hambali. ${ }^{6}$ Dalam bidang tasawuf Aswaja memiliki prinsip untuk dijadikan pedoman bagi kaumnya. Sebagaimana dalam masalah akidah dan fiqih, dimana Aswaja mengambil posisi yang moderat, tasawuf Aswaja juga demikian adanya. ${ }^{7}$

Dakwah Islam Rabmatan lil 'Alamin menurut Majalah Bangkit menyesuaikan dengan Q.S. An-Nahl [16]: 125.

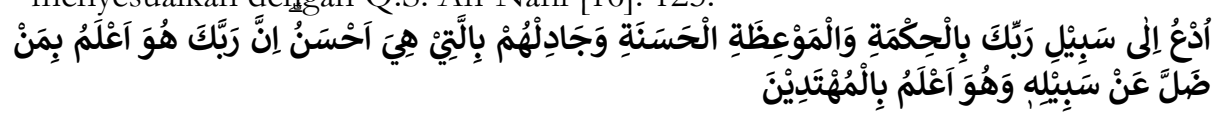

"Serulah (manusia) kepada jalan Tuhan-mu dengan hikmah dan pelajaran yang baik dan bantahlah mereka dengan cara yang baik. Sesunggubnya Tuhanmu Dialah yang lebih mengetahui tentang siapa yang tersesat dari jalan-Nya dan Dialah yang lebih mengetahui orang-orang yang mendapat petunjuk."

Dari ayat diatas kemudian Majalah Bangkit menafsirkannya sesuai dengan yang diajarkan Islam:

1. Dengan hikmah

Dakwah bukan dengan mencaci maki dan ucapan-ucapan yang kasar, tetapi dengan tutur kata dan bahasa yang santun. Isi dakwah tidak boleh membebani penerima dakwah. Seperti yang dijelaskan oleh Muhammadun, selaku pimpinan redaksi Majalah Bangkit. Maksud dari dari Isi dakwah tidak boleh membebani penerima dakwah adalah setiap orang sesuai dengan keadaan dan pemahaman serta sambutan dan ketaatannya. Termasuk hikmah dalam berdakwah adalah berdakwah dengan dasar ilmu, bukan kebodohan, memulai dengan perkara yang paling penting (sesuai dengan skala prioritas), lalu yang lebih penting daripada (yang sesudahnya) dan yang lebih dekat dengan alam pikiran mereka dan mudah dipahami, dengan cara (simpatik) yang lebih mendatangkan sambutan lebih baik, dengan penuh kelembutan dan persuasive.

\footnotetext{
${ }^{4}$ Taufiqul Hakim, Kamus Amtsilati (Jepara: Al Falah Ofcite, 2014), 26.

5Sirajuddin Abbas, I'tiqad Ablussunah Wal Jama'ah, Jakarta: Pustaka Tarbiyah Baru, 2008), 7. 2008), 7.

'Sirajuddin Abbas, I'tiqad Ablussunah Wal Jama'ah, (Jakarta: Pustaka Tarbiyah Baru,

${ }^{7}$ Muhammad Hisyam Kabbani, Tasawuf Dan Ibsan: Antivirus Kebatilan Dan Kedzaliman (Jakarta: Serambi, 2007), 63.
} 
2. Pelajaran yang baik

Dakwah harus memberikan pelajaran yang baik kepada seluruh alam. Dalam hal ini, berdakwah tidak boleh mencela, seorang da'i harus memberi nasihat, pengajaran, serta teladan yang baik dan benar. Da'i harus memberi kepuasan jiwa kepada sasaran dakwah. Sedangkan menurut redaksi Majalah Bangkit memilik prinsip bahwa dalam berdakwah mengajarkan mengenai perintah dan larangan dalam Islam, yang diiringi dengan targhib (anjuran keutamaan) dan tarhib (ancaman). Baik dengan (menyampaikan) kemaslahatan yang terkandung oleh perintah-petintah dan menghitunghitungnya dan bahaya yang terkandung dalam larangan-larangan dan menginventariskannya, atau dengan menyebutkan kemuliaan yang diraih oleh orang-orang yang menegakkan agama Allah dan penghinaan dan diterima orang yang tidak menjalankannya. Maupun dengan menyebutkan sesuatu yang telah Allah sediakan bagi orang-orang yang taat berupa balasan baik di dunia dan akhirat, dan sesuatu yang dipersiapkan oleh Allah bagi para pelaku maksiat, berupa hukuman dunia dan akhirat.

3. Bantahan dengan cara yang lebih baik.

Dakwah ini dilakukan ketika sasaran dakwah sudah tidak bisa ditaklukan dengan dua cara diatas. Cara ini boleh dilakukan tetapi tidak dengan mencela dan mengata-ngatai atau menjelek-jelekkan. Harus dengan kesabaran dan ketegasan. Yaitu cara-cara yang bisa lebih efektif agar dia menyambut dakwah secara nalar maupun lewat dalil naqli. Termasuk, mengemukakan argumentasi untuk menyerangnya dengan membawakan dalil-dalil yang dia yakini (selanjutnya dibantah satu persatu).

Untuk menyampaikan dakwah Islam Rahmatan lil 'Alamin Majalah Bangkit menggunakan cara yang sesuai ajaran Islam. Yang pertama dengan hikmah, jika dengan cara pertama masih belum tunduk, maka beralih ke cara yang kedua dengan pelajaran yang baik, jika dengan cara kedua masih belum tunduk juga, maka beralih dengan cara membantah tetapi dengan cara yang lebih baik, dengan bahasa yang lembut tetapi tegas.

\section{b. Gagasan Islam Rahmatan lil 'Alamin}

Pengertian Islam secara etimologi yaitu berasal dari bahasa Arab salima yang dibentuk menjadi kata aslama kemudian dibentuk lagi menjadi kata Islam (aslama yuslimu islaman) yang berarti selamat, aman, damai, patuh, berserah diri dan taat. Orang yang masuk Islam dinamakan muslim, yang sudah menyatakan dirinya telah taat, menyerahkan diri, dan patuh kepada Allah SWT. Orang yang menjalani aslama akan terjamin keselamatan dunia dan akhirat. ${ }^{8}$ Dari penjelasan singkat diatas dapat disimpulkan bahwa Islam dari segi bahasa adalah berserah diri, patuh, dan tunduk kepada Allah SW'T untuk mencapai kebahagiaan dunia dan akhirat. 
Islam merupakan agama wahyu yang terakhir, karena itu Islam agama yang paling lengkap. Islam diturunkan Allah melalui perantara Nabi Muhammad SAW yang penjelasan agamanya lebih luas dan menyeluruh karena Nabi Muhammad diutus untuk menyebarkan Islam bagi seluruh umat manusia. Islam yang dibawa oleh Nabi Muhammad SAW telah mempengaruhi seluruh aspek kehidupan manusia dan juga menjadi sebuah disiplin ilmu yang diajarkan diberbagai jenjang pendidikan. Karena muaranya ilmu itu untuk memberi manfaat dan memberi kasih sayang pada sesama. Maka visi rahmat juga dilandaskan untuk mengajarkan ilmu. Dan setiap agama pasti mengajarkan kasih sayang kepada sesama agar tercipta damai dan sejahtera.

Islam juga merupakan agama yang universal dan komprehensif, karena Islam menganugerahi kenyataan spiritual kepada umatnya yang sesuai dengan pemahaman manusia. Islam mempunyai aturan-aturan yang disusun sedemikian rupa sehingga setiap umat yang mau melaksanakannya akan memperoleh kehidupan yang mulia. ${ }^{9}$ Hampir semua agama menyebarkan kasih sayang kepada sesamanya. Alasannya manusia itu diperintahkan Tuhan untuk mengikuti Nabi dan Nabi diutus Allah untuk menyebarkan kasih sayang kepada sesama. Jika ada kasih sayang kepada sesama maka kedamaian akan tercipta, begitu sebaliknya jika tidak ada rahmat diantara sesama maka permusuhan, konflik, dan perpecahan yang akan tercipta.

Islam membawa manfaat kepada setiap orang dan setiap masyarakat, ${ }^{10}$ maka dari itu Islam memiliki prinsip Rahmatan lil 'Alamin yaitu rahmat bagi alam semesta. Islam Rahmatan lil 'Alamin memiliki makna yaitu "rabmat" yang jika disandarkan kepada Allah artinya adalah "kebaikan semata-mata" dan jika disandarkan manusia artinya menjadi "simpati semata". Sedangkan istilah "il 'alamin" secara harfiah diartikan "seluruh alam" maksdunya adalah seluruh unsur bumi yang berisi manusia, hewan, tumbuhan, benda-benda alam dan juga dunia jin sekalipun. Tetapi yang diutamakan dari maksud tersebut adalah semua hal yang berkaitan dengan aktivitas manusia. ${ }^{11}$

Pengertian Islam Rahmatan lil 'Alamin menurut Majalah Bangkit adalah Islam yang damai, adil, toleran dan sesuai dengan nilai-nilai aswaja. Jadi, Rabmatan lil 'Alamin merupakan konsep besar Islam. Rabmatan lil 'alamin ini merupakan nikmat yang diberikan Tuhan kepada makhluk-Nya di seluruh alam semesta yaitu manusia, tumbuhan, hewan, dan benda-benda yang ada di langit dan bumi. Nikmat untuk semua makhluk ciptaan Allah, termasuk orang-orang Non Islam. Sebagai seorang Muslim kita harus bisa membawakan Islam Rabmatan lil 'Alamin sesuai ajaran Nabi.

Istilah Islam Rahmatan lil 'Alamin merupakan istilah yang berpedoman pada ajaran Islam Al-Quran dan sunnah, karena Quran dan sunnah

${ }^{9}$ Ishom Fuadi Fikri, Universalitas Islam Dan Lokalitas Budaya Dalam Bingkai Islam Nusantara (Jurnal Tasawuf Dan Pemikiran Islam, Vol. 8, No. 1, Juni 2008), 63.

${ }^{10}$ Allamah Sayyid Muhammad Husain Thabathaba'i, Inilab Islam: Upaya Memahami Selurub Konsep Islam Secara Mudah (Jakarta: Pustaka Hidayah, 1992), 41.

11 Asep Maulana Rahimat, Metodologi Studi Islam: Memahami Islam Rabmatan Lil'alamin (Yogyakarta: Gerbang Media, 2018), 6. 
mengajarkan kita untuk Rahmatan lil 'Alamin. Dalam Al-Quran banyak sekali yang menyebutkan rahmat, bahkan Allah sediri sifatnya Rahman dan Rahim. Sementara dalam hadits juga sudah disebutkan sesuai dawuh Nabi tentang kasih sayang kepada sesama. Menjadi orang muslim harus saling mengasihi sesamanya tanpa melihat adanya satu perbedaan, karena sejatinya semua Makhluk dihadapan Allah itu sama.

Rahmatan lil 'alamin adalah saling memberi manfaat bagi yang lainnya. Islam membawa manfaat kepada setiap orang dan setiap masyarakat, ${ }^{12}$ maka Rabmatan lil 'Alamin adalah rahmat bagi alam semesta. Maksudnya adalah seluruh unsur bumi yang berisi manusia, hewan, tumbuhan, benda-benda alam dan juga dunia jin sekalipun. Tetapi yang diutamakan dari maksud tersebut adalah semua hal yang berkaitan dengan aktivitas manusia. Maka semua aktivitas manusia termasuk usahanya memenuhi kebutuhan hidup dengan prinsip tidak melanggar aturan Islam. ${ }^{13}$

Islam Rabmatan lil 'Alamin secara umum adalah rahmat seluruh alam yang bukan hanya menyelamatkan manusia tetapi alam lainnya. yang diselamatkan adalah hablum minallah, hablum minannas, dan hablum minal alam. ${ }^{14}$ Disini manusia sering tidak menyeimbangkan antara ketinganya. Sebagian besar manusia ada yang lebih mementingkan hubungannya dengan Allah, ada yang mementingkan hubungan dengan manusia, ada juga yang mementingkan hubungan kepada alamnya. Jika segala sesuatu itu Rahmatan lil 'alamin, tidak akan ada konflik seperti yang banyak terjadi dimasa sekarang. Konflik itu bermula sejak kasus serangan ke menara kembar WTC 9 September 2001, semenjak itu label radikal dan teroris sering dikaitkan kepada orang Islam, bahkan kepada agama Islam itu sendiri. Bahkan ada juga yang beranggapan bahwa Al Qur'an dan Hadits Nabi, memang mengajarkan orang Islam untuk melakukan kekerasan kepada orang lain. ${ }^{15}$ Semakin kesini semakin banyak propagandan mengenai Islam, organisasi-organsasi Islam lain menjadi salah satu penyebab propaganda tersebut. organisasi-organisasi tersebut banyak yang salah dalam menginterpretasikan makna Rahmatan lil 'Alamin yang sesungguhnya. Rahmatan lil 'Alamin itu berarti tidak boleh ada yang luput dari rahmat Allah.

Rabmatan lil 'Alamin semakin hari justru semakin sempit cakupannya. ${ }^{16}$ Hal itu dikarenakan banyak manusia yang tidak mengusung Rahmatan lil 'Alamin dalam kehidupan sehari-hari. Manusia sekarang itu egois, mereka selalu

12 Allamah Sayyid Muhammad Husain Thabathaba'i, Inilah Islam: Upaya Memahami Selurub Konsep Islam Secara Mudah (Jakarta: Pustaka Hidayah, 1992), 41.

${ }^{13}$ Asep Maulana Rahimat, Metodologi Studi Islam: Memahami Islam Rabmatan Lil'alamin (Yogyakarta: Gerbang Media, 2018), 6.

14 Dr. Phil Sahiron Syamsudin, "Kajian Islam Terkait Lingkungan Harus Diseimbangkan" Dalam Https://Republika.Co.Id/Berita/Koran/DialogJumat/16/03/24/O4jik72-Dr-Phil-Sahiron-Syamsuddin-Kajian-Islam-Terkait-LingkunganHarus-Diseimbangkan. Diakses Pada 14 Maret 2020.

${ }^{15}$ Ismail Yahya, "Islam Rahmatan Lil "Alamin", dalam https://IainSurakarta.Ac.Id/Islam-Rahmatan-Lilalamin/. Diakses Pada Tanggal 17 Juli 2020.

${ }^{16}$ Emha Ainun Nadjib, Islam Itu Rabmatan Lil 'Alamin Bukan Untuk Kamu Sendiri, (Jakarta: PT.Mizan Publika, 2019), 7. 
mementingkan diri sendiri, lebih mementingkan nafsu ke egoisan mereka daripada menjadi "rahmat" bagi sesama manusia.

Hal ini juga dijelaskan oleh Emha Ainun Najib dalam bukunya yang berjudul Islam Rahmatan lil 'Alamin bukan untuk kamu sendiri ${ }^{17}$ bahwa manusia sekarang itu maunya menang sendiri, mau kaya sendiri, mau masuk surga sendiri, mau unggul sendiri, mau hebat sendiri, sehingga semua di rekrut, semua dijual, dijadikan brand supaya terlihat lebih hebat dari orang lain.

Maka dari itu manusia masih perlu mengkaji lebih dalam mengenai Islam Rahmatan lil 'Alamin agar menjadi rahmat dan membawa keberkahan yang bisa menyeimbangkan dalam berhubungan dengan Allah, manusia dan alamNya. Rabmatan lil 'alamin adalah saling memberi manfaat bagi yang lainnya. Rahmatan lil 'alamin tidak bisa dijadikan pedoman primordial ${ }^{18}$ karena semua makhluk hidup di bumi membutuhkan itu. Sementara di dunia ini tidak mungkin semua orang bisa berlaku damai, pastilah ada sebagian orang yang hidupnya ingin merusak, memusuhi dan membuat api permusuhan kepada orang lain.

Pernyataan bahwa Islam adalah agama yang Rahmatan lil 'Alamin terdapat pada firman Allah pada surat Q.S. Al-Anbiya [21]: 107.

\section{ما أَرْسَلْناكَ إلاََّ رَحْمَةً لِلْعالَمِينَ}

"Kami tidak mengutus engkau, Wahai Muhammad, melainkan sebagai rahmat bagi selurub manusia"

Berdasarkan pemahaman diatas adalah bahwa Islam ada bukan untuk menghadirkan bencana melainkan untuk keselamatan, kesejahteraan dan untuk kebahagiaan manusia lahir dan batin. Kebenaran Islam sebagai rahmat bagi manusia bisa dibuktikan dengan Islam mampu merubah sifat manusia dari hina menjadi mulia, menunjukkan jalan yang baik ketika tersesat. Jadi, menjadi Rahmatan lil 'alamin itu bukan hanya untuk orang Islam saja, tetapi untuk seluruh manusia dan alam semesta.

Maka dari itu, hal tersebut menjadi sebuah tantangan bagi Majalah Bangkit untuk menyebarkan Islam yang Rahmatan lil 'Alamin melalui majalah. Di dunia ini tidak mungkin semua orang bisa berlaku damai, pastilah ada sebagian orang yang hidupnya ingin merusak, memusuhi dan membuat api permusuhan kepada orang lain. Itu adalah salah satu tantangan paling serius dari dulu sampai sekarang. Hal itu terjadi tidak hanya dalam agama saja tetapi dalam sebuah kelompok pun juga ada yang tidak mengusung Rahmatan lil 'Alamin.

Tantangan yang paling banyak dihadapi oleh Majalah Bangkit dalam mengusung Islam Rahmatan lil 'Alamin yaitu kekuasaan, karena kekuasaan itu sifatnya nafsu yang serakah sedangkan nafsu yang serakah itu seringkali merusak. Itu otomatis akan mengalahkan atau menjatuhkan orang lain. Itulah

17 Emha Ainun Nadjib, Islam Itu Rahmatan Lil 'Alamin Bukan Untuk Kamu Sendiri, (Jakarta: PT.Mizan Publika, 2019), 7.

18 Primordial atau primordialisme adalah perasaan kesukuan yang berlebihan dalam KBBI dalam https://id.wikipedia.org/wiki/primordialisme. Diakses pada 3 juli 2020. 
tantangan dalam mengenalkan Islam Rahmatan lil 'Alamin sejak dulu sampai sekarang."

Pada kenyataannya tantangan untuk mengenalkan Islam Rabmatan lil 'Alamin dari dulu sampai sekarang tidak berubah. Justru semakin modern zaman, semakin sulit pula untuk meraih kejayaan Islam. Jadi, cara yang sesuai untuk mengenalkan Islam Rahmatan lil 'Alamin saat ini dengan mengusung keselarasan antara syari'at Islam dan tuntutan dunia modern. Kita akan memiliki isu-isu tentang banyak hal dan juga konflik-konflik tak berujung yang begitu penting bagi Islam saat ini, sambil mengharapkan adanya solusi bersama dalam upaya merealisasikan era yang damai dan harmonis di antara sesama umat beragama. ${ }^{19}$ Solusi untuk menghadapi Islam di masa sekarang yaitu dengan menjadikan Islam Rahmatan lil 'Alamin sebagai pelindung dalam berdakwah, dengan itu Islam juga akan menciptakan visi dengan penuh kelembutan dan kedamaian secara bertahap.

\section{c. Karakteristik Islam Rahmatan lil 'Alamin}

Karakteristik Islam Rahmatan lil 'Alamin menurut Majalah Bangkit berdasarkan wawancara dengan Muhammadun pada 2 Juli 2020 adalah sebagai berikut:

1. Tidak ada kekerasan

Maksudnya adalah agama Islam tidak pernah mengajarkan umatNya untuk berbuat kekerasan dalam bentuk apapun. Entah itu kekerasan fisik atau kekerasan batin sekalipun. Dalam Islam tindakan kekerasan ini hukumnya haram dan terlarang. Karena hal itu akan mendatangkan berbagai macam persoalan di tengah masyarakat. Jika kekerasan terjadi, tidak akan tercipta kedamaian, keharmonisan dan kerukunan.

Saat ini Islam Rahmatan lil 'Alamin justru dipandang sebagai agama yang menakutkan. Persepsi itu muncul karena pada kenyataannya kekerasan yang sering terjadi di negara yang mayoritas berpenduduk Muslim, bahkan di negara kita sendiri negara Indonesia. Perilaku kaum Muslimin membuat Islam menjadi buruk dipandangan agama lain. Perseteruan di kalangan umat Islam yang tak kunjung selesai bahkan semakin tajam. Hal tersebut terjadi karena beberapa kelompok Muslim yang menyeleweng dengan konsep Islam di Indonesia. Mereka ingin membangun Islam dengan konsepnya bangsa Arab. ${ }^{20}$

Pada kenyataan ini, sebagai Muslim kita tidak bisa memberi klarifikasi bahwa apa yang dilakukan pelaku kekerasan sama sekali tidak sesuai dengan nilai-nilai Islam. Faktanya, banyak kelompok radikal yang mengkampanyekan kekerasan dan kebencian dengan atas nama Islam.

\footnotetext{
${ }^{19}$ Yahiya Emerick, Memahami Islam (Jakarta: PT. Ina Publikatama, 2007), 390.

${ }^{20}$ Emha Ainun Nadjib, Islam Itu Rabmatan Lil 'Alamin Bukan Untuk Kamu Sendiri (Jakarta: PT.Mizan Publika, 2019), 6.
} 
Mereka mengutip dari ayat al-Qur'an yang diterjemahkan sendiri sesuai apa yang mereka pahami dan sumber yang tidak jelas. ${ }^{21}$

2. Mengutamakan pedamaian

Setiap agama mengajarkan kepada umatnya untuk hidup rukun dan berdamai. Agama Islam mengajarkan umatnya untuk hidup saling mencintai, menegakkan perdamaian dan bertoleransi antar sesama manusia tanpa memandang dari mana ia berasal, entah itu sukunya, bangsanya maupun agamanya. Dalam Islam perdamaian merupakan kunci menjalin hubungan yang baik antar manusia. Karena dengan perdamaian akan tercipta kehidupan yang nyaman dan sejahtera. Dengan perdamaian manusia akan hidup dengan aman, penuh ketenangan dan kebahagiaan.

Tetapi faktanya masih banyak terjadi permusuhan antara kelompok satu dengan yang lain. Hal ini terjadi, lagi-lagi karena isu-isu radikalisme Islam yang sudah mendunia, bahkan di negara-negara barat seperti Amerika, menyebut bahwa Islam adalah agama terorisme. Islam sudah menjadi fenomena yang perlu dicurigai. Sehingga Islam terus menerus dipojokkan oleh non-Muslim. Padahal Islam yang sebenarnya adalah Islam yang Rabmatan lil 'Alamin, Islam sangat menjunjung tinggi perdamaian. Islam sama sekali tidak mengajarkan radikalisme atau kekerasan, Islam tidak memiliki keterkaitan dengan radikalisme. ${ }^{22}$

Sebagai seorang Muslim tentu kita wajib mengembalikan citra Islam sebagaimana yang telah diajarkan oleh Nabi Muhammad SAW. Sebagai Nabi yang mengemban misi Rabmatan lil 'Alamin, Nabi Muhammad SAW mempunyai kunci dalam berdakwah yaitu dengan menebar kasih sayang, kelembutan kepada sesama, dan akhlak yang agung. ${ }^{23}$ Karena dengan hal itu akan tercipta kehidupan yang damai. Maka kehadiran Nabi Muhammad SAW diharapkan mampu membawa keberkahan kepada umat manusia, bukan hanya umat Islam tetapi semua ciptaan Allah SW'T, termasuk, jin, binatang, tumbuhan dan benda-benda yang ada dilangit dan bumi.

3. Persaudaraan

Hubungan antar sesama manusia disebut persaudaraan. Dengan persaudaraan inilah antar sesama manusia akan bersatu padu dengan baik. Persaudaraan ini dilandasi oleh ajaran Islam Rahmatan lil 'Alamin. Persaudaraan dibangun dengan tujuan agar manusia saling bekerjasama dan saling tolong menolong untuk berbuat kebaikan dan kebenaran, bukan untuk menciptakan permusuhan atau melakukan perbuatan buruk. Dengan kebaikan dan kebenaran ini kehidupan yang damai dan makmur akan

\footnotetext{
${ }^{21}$ Sunaryo, https://www.beritasatu.com/ramadansatu/jalan-pulang/492617-agamadan-kekerasan. Diakses Pada Tanggal 18 Juli 2020.

${ }^{22}$ Nur Hidayat, Nilai-Nilai Ajaran Islam Tentang Perdamaian: Kajian Antara Teori dan Praktek (Jurnal Aplikasi Ilmu-Ilmu Agama, Vol. 17, No.1, Tahun 2017), 16.

${ }^{23}$ Gus Muwafiq, Islam Rabmatan Lil 'Alamin, (Yogyakarta: Al Barokah, 2019), 114118.
} 
tercipta. Persaudaraan merupakan kesadaran manusia selama hidup berdampingan untuk mewujudkan Islam yang Rahmatan lil 'Alamin.

Menjadi manusia Rahmatan lil 'Alamin itu harus Anfa'ubum linnas (manusia yang bermanfaat bagi manusia lainnya), Anfa'abum lil-alamin (manusia yang bermanfaat untuk seluruh alam). Anfa'ubum lin-nas merupakan prinsip bahwa ukuran jabatan manusia tidak akan ada artinya jika tidak bermanfaat bagi orang lain. ${ }^{24}$ Rabmatan lil 'Alamin itu tidak pilih kasih, tidak memandang baik-buruknya orang, semuanya harus mendapat rahmat. Bahkan orang korupsi, orang mencuri, dan orang-orang yang berbuat maksiat juga harus diberi rahmat. Karena Rahmatan lil 'Alamin tidak boleh dijadikan identitas suatu kelompok tertentu, melainkan milik bersama. ${ }^{25}$

4. Saling menghargai

Islam Rahmatan lil 'Alamin adalah Islam yang mengajarkan untuk saling menghargai antar sesama manusia tanpa memandang suku, bangsa dan agamanya. Islam adalah agama yang toleran. Sebagai seorang Muslim sudah seharusnya untuk bersikap saling menghargai atar sesama. Dengan menghormati orang lain, maka kita akan dihormati oleh orang lain juga. Menghargai adalah salah satu upaya membina kerukunan hidup antar sesama. Menumbuhkan sikap menghargai merupakan sikap yang terpuji. Sikap menghargai harus didasari dengan jiwa yang ikhlas.

Rabmatan lil 'Alamin harus saling menghargai pendapat orang atau kelompok. Sekalipun pendapat itu tidak kita sukai bahkan terdengar asing. Kita harus berusaha untuk memberikan peluang untuk mereka yang berpendapat. Karena berbeda pendapat itu juga rahmat yang jika kita sikapi dengan benar maka akan menambah ilmu pengetahuan dan akan membawa kita lebih dekat dengan kebenaran. ${ }^{26}$ Karena Islam adalah agama yang memudahkan. Dalam Islam beragama bukan dijadikan pilihan untuk mengambil jalan hidup yang sulit dan anti kemajuan. ${ }^{27}$

5. Hal-hal yang sifatnya baik dan memberi nilai lebih

Islam adalah agama rahmat. Setiap hal yang baik dan bermanfaat bagi manusia adalah ajaran Islam Rahmatan lil 'Alamin yang sesungguhnya. Islam adalah agama yang paling lengkap dibanding agama-agama yang lain. Islam memberikan tuntunan hidup manusia dari persoalan yang kecil sampai pada urusan yang sulit. Islam hanya mengajarkan umat-Nya dalam

${ }^{24}$ Emha Ainun Nadjib, Islam Itu Rabmatan Lil 'Alamin Bukan Untuk Kamu Sendiri, (Jakarta: PT. Mizan Publika, 2019), 38.

${ }^{25}$ Emha Ainun Nadjib, Islam Itu Rabmatan Lil 'Alamin Bukan Untuk Kamu Sendiri, (Jakarta: PT. Mizan Publika, 2019),179.

${ }^{26}$ Haidar Bagir, Islam Tuban Islam Manusia: Agama Dan Spiritualitas Di Zaman Kacau, (Bandung: PT. Mizan Pustaka, 2017), 17.

${ }^{27}$ Haidar Bagir, Islam Tuhan Islam Manusia: Agama Dan Spiritualitas Di Zaman Kacau, (Bandung: PT. Mizan Pustaka, 2017), 17. 
hal-hal kebaikan seperti perdamaian, saling menghargai, saling menyayangi tanpa adanya permusuhan dan kekerasan.

Rabmatan lil 'Alamin adalah saling memberi ruang antar manusia. Itulah yang dinamakan rahmat. Rahmatan lil 'Alamin itu harus kita jaga bersama, karena semua manusia butuh itu. Apaun yang manusia lakukan itu akan menjadi Rahmatan lil 'Alamin. Lakukanlah sesuatu yang mempunyai kemaslahatan yang tinggi sedangkan mudharatnya rendah. ${ }^{28}$ Karena pada hakikatnya manusia itu hidup dalam kesatuan antara kemarin, sekarang, dan besok. Pedoman dasar Rahmatan lil 'Alamin adalah bahwa manusia tidak bisa hidup di luar Allah. Mau melakukan hal apapun, Allah selalu terlibat didalamnya. Karena tidak ada satu hal pun, tidak ada satu benda pun, tidak ada satu partikel pun yang bukan buatan Tuhan. ${ }^{29}$

\section{Kesimpulan}

Majalah Bangkit dalam mendakwahkan Islam Rahmatan lil 'Alamin melalui media majalah dan juga Bangkit media. Dakwah tersebut disajikan dalam bentuk konten-konten yang dimuat di majalah atau di Bangkit media. Bangkit mengekspos konten Islam Rahmatan lil 'Alamin sesuai dengan prinsip-prinsip NU (Nahdlatul Ulama). Majalah Bangkit banyak mengupas hal-hal terkait Rahmatan lil 'Alamin yang ditentang oleh beberapa kelompok lain. Islam Rabmatan lil 'Alamin perspektif Majalah Bangkit yaitu Islam yang damai, adil, toleran dan sesuai dengan nilai-nilai aswaja. Jadi, Rabmatan lil 'Alamin merupakan konsep besar Islam yang sesuai dengan ajaran NU (Nahdlatul Ulama). Rahmatan lil 'alamin adalah saling memberi manfaat bagi yang lainnya. Islam membawa manfaat kepada setiap orang dan setiap masyarakat, maka Rahmatan lil 'Alamin adalah rahmat bagi alam semesta. Perspektif Islam Rabmatan lil 'Alamin Majalah Bangkit juga berkesinambungan dengan karakteristik Islam Rahmatan lil 'Alamin diantaranya yaitu tidak ada kekerasan, mengutamakan perdamaian, persaudaraan, saling menghargai dan hal-hal yang sifatnya baik.

\section{Daftar Pustaka}

Abbas, Sirajuddin. I'tiqad Ablussunah Wal Jama'ah. Jakarta: Pustaka Tarbiyah Baru, 2008.

Bagir, Haidar. Islam Tuban Islam Manusia: Agama dan Spiritualitas di Zaman Kacau. Bandung: PT. Mizan Pustaka, 2017.

Emerick, Yahya. Memahami Islam. Jakarta: PT. Ina Publikatama, 2007.

Harjani Hefni. "Makna Dan Aktualisasi Dakwah Islam Rahmatan Lil 'Alamin Di Indonesia". Jurnal Ilmu Dakwah, Vol.11, No. 1 (2017).

Ishom Fuadi Fikri. "Universalitas Islam dan Lokalitas Budaya dalam Bingkai Islam Nusantara." Jurnal Tasawuf dan Pemikiran Islam, Vol. 8, No. 1 ( 2008)

${ }^{28}$ Gus Muwafiq, Islam Rahmatan Lil 'Alamin (Yogyakarta: Al Barokah, 2019), 180.

${ }^{29}$ Gus Muwafiq, Islam Rabmatan Lil 'Alamin (Yogyakarta: Al Barokah, 2019), 185186. 
Kabbani, Muhammad Hisyam. Tasawuf dan Ibsan: Antivirus Kebatilan dan Kedzaliman. Jakarta: Serambi, 2007.

Muhamamd Makmun Rosyid, "Islam Rahmatan Lil'alamain Perspektif KH. Hasyim Muzadi”. Jurnal Episteme, Vo.l 11, No. 1 (2016).

Muhammad Rifat. "Dakwah dan Toleransi Umat Beragama: Dakwah Berbasis Rahmatan Lil'alamin". Jurnal Alhadharah, Vol. 13, No. 26 (2014).

Muhdlor, Ahmad Zuhdi. Majalab Bangkit. https://www.nu.or.id/post/read/40223/majalah-bangkit. (Diakses pada 14 Oktober 2012.)

Muwafiq, Gus. Islam Rahmatan lil 'Alamin. Yogyakarta: Al Barokah, 2019.

Nadjib, Emha Ainun. Islam Itu Rabmatan lil 'Alamin Bukan Untuk Kamu Sendiri. Jakarta: PT.Mizan Publika, 2019.

Nur Hidayat. "Nilai-Nilai Ajaran Islam Tentang Perdamaian (Kajian antara Teori dan Praktek).” Jurnal Aplikasi Ilmu-Ilmu Agama. Vol. 17, No.1, (2017).

Rahimat, Asep Maulana. Metodologi Studi Islam: Memahami Islam Rahmatan lil 'Alamin. Yogyakarta: Gerbang Media, 2018

Razak, Nasaruddin. Dienul Islam. cet. II, Bandung: Al-Ma'arif, 1997.

Sunaryo, https://www.beritasatu.com/ramadansatu/jalan-pulang/492617-agamadan-kekerasan.html. (Diakses Pada Tanggal 18 Juli 2020)

Syamsudin, Dr.Phil Sahiron. Kajian Islam Terkait Lingkungan Harus Diseimbangkan. https://republika.co.id/berita/koran/dialogjumat/16/03/24/o4jik72-dr-phil- sahiron-syamsuddin-kajianislam-terkait-lingkungan-harus-diseimbangkan. (Diakses Pada 14 Maret 2020)

Thabathaba'I, Allamah Sayyid Muhammad Husain. Inilab Islam: Upaya Memahami Selurub Konsep Islam Secara Mudah. Jakarta: Pustaka Hidayah, 1992.

Yahya. Ismail. Islam Rahmatan lil 'Alamin. https://iain-surakarta.ac.id/islamrahmatan-lilalamin. (Diakses Pada Tanggal 17 Juli 2020)

Zainuddin. "Dakwah Rahmatan Lil'alamin: Kajian Tentang Tolransi Beragama Dalam Surat Alkafirun". Jurnal Dakwah, Vol. X, No. 1 (2009). 
52 Jurnal Dakwah dan Komunikasi, Vol.6 No.1, 2021

Halaman ini sengaja di kosongkan 